\title{
CRITICAL ANALYSIS OF CAUSATIVE FACTORS OF FEMALE INFERTILITY
}

\author{
Sree Renjini M G $\mathbf{G}^{\mathbf{2}}$ \\ ${ }^{I} P G$ Scholar, Department of Prasuthi Tantra \& Streeroga, Sri Dharmasthala Manjunatheshwara College of
} Ayurveda and Hospital, B M Road, Thanniruhalla, Hassan-573201

Madhu $\mathbf{M}^{2}$

${ }^{2}$ Associate Professor, Department of Prasuthi Tantra \& Streeroga, Sri Dharmasthala Manjunatheshwara College of Ayurveda and Hospital, B M Road, Thanniruhalla, Hassan-573201

\section{Gayathri Bhat $\mathbf{N} \mathbf{V}^{3}$}

${ }^{3}$ Professor and Head, Department of Prasuthi Tantra \& Streeroga, Sri Dharmasthala Manjunatheshwara College of Ayurveda and Hospital, B M Road, Thanniruhalla, Hassan-573201

DOI: https://doi.org/10.36713/epra3854

\begin{abstract}
Background: Stree Vandhyatva (female infertility) accounts for $50 \%$ of infertility cases seeking treatment across the globe. Ayurveda attributes various causative factors including dietary, behavioural and psychological which may cause the imbalance of the Garbhasambhavasamagri (Ritu, Kshetra, Ambu and Beeja).Rasa Dushti due to Agnimandya or any underlying cause can also lead to Artavadushti thereby affecting the fertility in females. Objectives: To analyse the causative factors of female infertility among 250 subjects who visited the Outpatient and Inpatient Department of Prasuthi Tantra \& Streeroga of Sri Dharmasthala Manjunatheshwara College of Ayurveda and Hospital, Hassan. Methodology: The study was designed as a retrospective study using data previously gathered from 250 females who visited the Outpatient and Inpatient Department of Prasuthi Tantra \& Streeroga of Sri Dharmasthala Manjunatheshwara College of Ayurveda and Hospital, Hassan. Seeking infertility treatment. Results: Among 250 cases analysed, $18 \%$ of subjects had a history of repeated abortions and $30 \%$ of subjects had menstrual irregularities. $24 \%$ of female infertility cases were associated with Polycystic Ovaries, $12 \%$ had associated thyroid dysfunction and another 15\% were associated with other abnormalities of reproductive tract like fibroid uterus, endometriosis, adenomyosis and uterine anomalies. Conclusion: From the data collected, the causative factors of female infertility were analysed and concluded that polycystic ovaries, a lifestyle disorder is the most common cause which can be prevented by following proper Pathyapatha as per Ayurveda. A close association was also noted between thyroid dysfunction and female infertility. Keywords: Ayurveda, Streeroga, Female infertility, Garbhasambhavasamagri, Polycystic ovaries.
\end{abstract}




\section{INTRODUCTION}

Fertility is a direct indicator of reproductive health in females. Reproductive health refers to the condition of well-being physically, mentally and socially in all aspects relevant to reproductive processes. The WHO estimates the overall prevalence of primary infertility in India to be between 3.9 and 16.8 per cent. ${ }^{1}$ According to the Indian Society of Assisted Reproduction, infertility currently affects about 10 to 14 percent of the Indian population, with higher rates in urban areas where one out of six couples is impacted. ${ }^{2}$ Nearly 27.5 million couples actively trying to conceive suffer from infertility in India. ${ }^{3}$

In the present scenario, most of the couples spend a portion of their lives attempting to avoid unplanned pregnancies, and assume that shifting gears from preventing pregnancy to planning conception and childbirth will proceed in a relatively smooth and orderly fashion. A failure to conceive, then, is a major life stressor, which can wreak havoc on otherwise well-adjusted couples. Infertility is thus a major social problem and it is important to look into the various causes and other factors influencing fertility so that effective treatment options are planned.

Ayurveda terms female infertility as Stree Vandhyatva and attributes various causative factors like improper functioning of $V a y u$, lack of clarity in the functioning of Hrdaya and abnormality in any one among the Shadbhavas (matruja, pitruja,atmaja, satvaja, satmyaja and rasaja). The important factors in females responsible for conception are Rtu (season or fertile period), Kshetra or healthy reproductive tract, Bija i.e sperm and ovum, and $A m b u$ (nutrient fluid) and most important of all Soumanasya i.e a happy and positive mind.

Vandhyatva is one among the 80 diseases of Vataja origin mentioned in Ayurvedic Classics. Conception is assumed to be hampered due to the non-acceptance of the sperm or the fertilized ovum due to Dushta Vayu as in various Yoni Vyapat conditions and due to destruction of the Bijarupi Artava (ovum) as in Artavadushti conditions. Apathyaahara sevana and Agnimandya leading to Rasadushti can be a direct cause for Artavadushti followed by infertility. Sapraja is the term mentioned for Secondary infertility for which specific causative factors have been mentioned like Yoni pradosha (abnormalities of the genital tract), Mano abhitapa (any psychological abnormality), abnormal Sukra (sperm), Asrk (ovum), Ahara (diet), Vihara (regimen), Akalayoga (improper season or time of coital act) and Balakshaya (general debility). ${ }^{4}$

In clinical practice, the most common causes of infertility include anovulation due to polycystic ovaries, tubal factors, uterine factors, associated thyroid dysfunction or other unknown factors.

\section{AIMS \& OBJECTIVES}

The purpose of this study was to analyse the major causes of infertility in 250 females who visited the Outpatient and Inpatient Department of Prasuti Tantra \& Streeroga, Sri Dharmasthala Manjunatheshwara College of Ayurveda and Hospital, Hassan.

\section{MATERIALS AND METHODS}

The study population included 250 infertile women who approached the Outpatient and Inpatient Department of Prasuti Tantra \& Streeroga Sri Dharmasthala Manjunatheshwara College of Ayurveda and Hospital, Hassan during the year 2017 seeking infertility treatment.

Detailed history was collected using specially designed casesheet format from 250 health seekers who approached us for infertility treatment from January 2017 to December 2017. All routine examinations were done. Specific gynaecological examinations needed according to the condition were done in each case. Data was collected from previous investigation reports. Lacking necessary investigations were sent for. All necessary data was collected and documented systematically.

The causative factors of female infertility were analysed from the data collected. Critical analysis was done of any pathological condition that may lead to infertility or having a close association with it and the results were recorded in percentage.

\section{RESULTS}

Among 250 subjects analysed, $8 \%$ were cases of secondary infertility and $92 \%$ primary infertility. $18 \%$ of subjects had a history of repeated abortions and $12 \%$ had a history of one abortion. $30 \%$ of cases were associated with irregularities of the menstrual cycle like epimenorrhea, oligomenorrhea, menorrhagia and $4 \%$ had complaints of dysmenorrhea. 


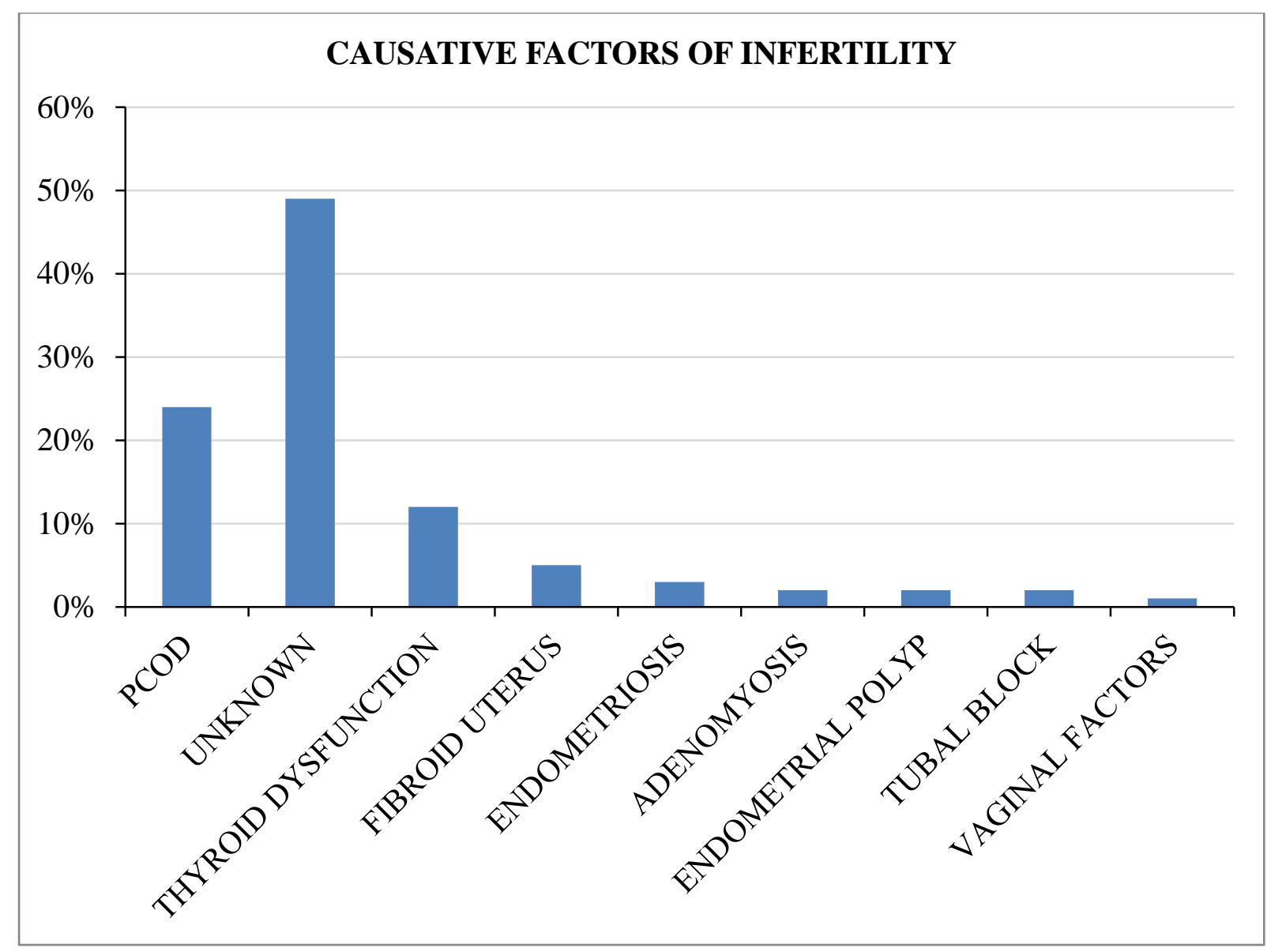

Figure 1: Chart representing various causative factors of infertility.

$24 \%$ of female infertility cases were associated with Polycystic Ovaries which is the highest among all and $12 \%$ had associated thyroid dysfunction. Another $15 \%$ were associated with other abnormalities of reproductive tract like fibroid uterus $(5 \%)$, septate vagina endometriosis, adenomyosis, endometrial polyp and tubal block ( $2 \%$ each).In rest $49 \%$ of subjects, no apparent causative factors were elicited and hence is assumed to be caused due to abnormalities of malefactors or unexplained infertility.

\section{DISCUSSION}

Infertility is defined as the failure to conceive within one or more years of regular unprotected coitus. 5 The total fertility rate for India, measured as the number of children born to a woman, has fallen from 4.97 during $1975-80$ to 2.3 for the current period of 2015-20. ${ }^{6}$ The evidence for changes in the prevalence of infertility is difficult to establish. Studies have indicated an overall pattern of decreasing fertility with increasing female literacy rates. More educated women are more likely to postpone marriages and childbirth. They are also likely to opt for smaller family size and with the increase in per capita income, there is a change in the lifestyle of both the urban and the rural populations. Lack of exercise and a sedentary lifestyle has led to an increase in obesity and hormonal disorders like PCOS.
As per a study was done in England in 1985, Failure of ovulation (amenorrhoea or oligomenorrhoea) occurred in $21 \%$ of cases of infertility and tubal damage in 14\%. Endometriosis accounts for infertility in $6 \%$, cervical mucus defects or dysfunction in $3 \%$, and coital failure in up to $6 \%{ }^{7}$

In a study conducted in France in 1988, the main causes of female infertility were found to be ovulation disorders $(32 \%)$ and tubal damage $(26 \%)$, Infertility was also found to be caused by disorders in both the male and female partners together in 39\% of cases. The woman alone was responsible for infertility in one-third of cases and the man alone in one-fifth. Unexplained infertility was found in $8 \%$ of the couple's surveyed. ${ }^{8}$

In a study done in Western Siberia in 1998, the most frequent causes of female infertility were disturbances to tubal patency (36.5\%) and pelvic adhesions (23.6\%). Endocrine pathology was found in $32.8 \%$ of cases. $^{9}$

A study was done in Mongolia in 2002 states that in $45.8 \%$ of couples, infertility was due to a female factor and in $25.6 \%$ of cases, infertility was due to a malefactor. $9.8 \%$ of couples had no demonstrable cause in either partner and $18.8 \%$ of couples had an infertility diagnosis in both partners. In the females, the prevalence of a past history of sexually transmitted infection (STI) and pelvic inflammatory disease were $33.5 \%$ and $25.1 \%$, respectively. ${ }^{10}$ 
As per a Study in Greece done in 2009, analysing the causes of infertility, $27.4 \%$ of the problems were due to fallopian tubes dysfunction, followed infertility of unknown cause in $24.5 \%$ of the cases, $20 \%$ were due to disorders of menstruation, $9.1 \%$ due to problems of the uterus, $2.7 \%$ due to sexual disorders, another $2.7 \%$ because of age and in a very small percentage, infertility was caused by ovarian failure. ${ }^{1}$

In a study done in North India in 2007, 140 women with an indication for IVF were analyzed for Genital TB. Of these, 70 patients $(50 \%)$ had tubal factor infertility and the prevalence of genital tuberculosis in tubal factor infertility was 34 out of $70(48.5 \%) .^{12}$
In a study done in Bihar in 2017, $11 \%$ of women with infertility had evidence of PCOD. 24\% of women had hypothyroidism (TSH more than 4.5 IU/L) and $13 \%$ were found to have a high level of prolactin i.e. $>25 \mathrm{ng} / \mathrm{ml}$. Nearly $8 \%$ of women had a high level of FSH i.e. more than $10 \mathrm{IU} / \mathrm{L}$ which is an indicator of ovarian resistance. In nearly $16 \%$ women one fallopian tube was found blocked and $8 \%$ had both tubes blocked in hysterosalpingography. ${ }^{13}$

In the present study, age factors and duration of family life were analysed as in figure 2 and 3. The highest prevalence of infertility is reported in the most fertile age group i.e. 20-30 yrs of age and the least duration of married life i.e. 5 yrs.

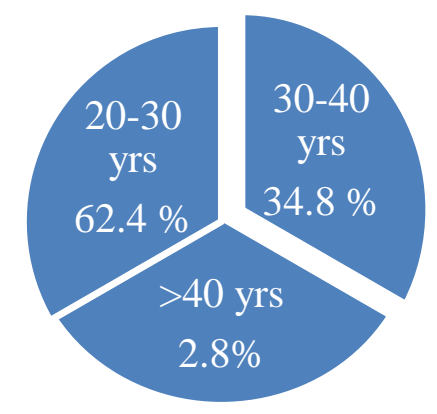

Figure 2: Prevalence of infertility in various age groups in married couples.

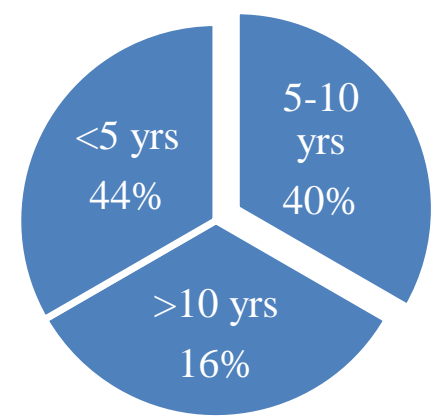

Figure 3: Prevalence of infertility according to the duration of married life.

Generally, tubal factors account for around $25-35 \%$ of infertility cases but in the present study, only $2 \%$ of cases were found to have a tubal blockage. Uterine factors were found to have a higher prevalence in cases with infertility in the population studied. Endocrinological causes also were found to be higher in comparison. These changes may be attributed to factors like specific diet or lifestyle of the people in the area or any environmental factors affecting the same.

In $49 \%$ of subjects, no apparent causative factors were elicited. Only the female partner was assessed in the present study, and hence it may be assumed that infertility in these cases may be due to abnormalities in their male counterparts.
The overall analysis states that anovulation due to polycystic ovaries and tubal pathology contributes to the majority of female infertility cases all over the world. Uterine anomalies and endocrinal pathologies also have a major influence on fertility.

\section{CONCLUSION}

Based on the present study, it can be concluded that the most common cause of female infertility in the population studied is Polycystic Ovaries followed by any abnormalities of the uterus, tubes, vagina and lastly thyroid dysfunction. 


\section{REFERENCES}

1. Prevalence $\mathbb{E}^{\circ}$ correlates of primary infertility among young women in Mysore, India, https://www.ncbi.nlm.nih.gov/pmc/articles/PMC32372 40 Indian J Med Res. 2011 Oct; 134(4): 440-446.

2. India's Hidden Infertility Struggles, https://thediplomat.com/2018/05/indias-hiddeninfertility-struggles

3. https://timesofindia.indiatimes.com/lifestyle/parenting/getting-pregnant/27-5-million-couplesin-india-suffering-frominfertility/articleshow/63938393.cms

4. Ayurvediya Prasuthi Tantra \& Striroga, Part 2 By Prof. Premvathi Tewari, Published by Chaukhambha Orientalia, Varanasi.

5. D C Dutta's Textbook of Gynaecology including Contraception edited by Hiralal Konar, $7^{\text {th }}$ edition, Jaypee Brothers Medical Publishers (P) Ltd

6. Infertility - A Growing Concern For India http://www.businessworld.in/article/Infertility-AGrowing-Concern-For-India/O9-O4-2018-145838

7. Population Study OfCauses, Treatment, And Outcome Of Infertility, $M$ G R Hull, C M A Glazener, N J Kelly, D I Conway, $P \quad A$ Foster, $R \quad A$ Hinton, https://www.ncbi.nlm.nih.gov/pmc/articles/PMC14187 55

8. Incidence and main causes of infertility in a resident population (1,850,000) of three French regions (19881989).Thonneau $P$, Marchand $S$, Tallec A, Ferial ML, https://www.ncbi.nlm.nih.gov/pubmed/1757519

9. Estimation of the prevalence and causes of infertility in Western Siberia Philippov OS, Radionchenko AA, Bolotova $\quad V P$, Voronovskaya NI, Potemkina $T V$ https://www.ncbi.nlm.nih.gov/pubmed/9648359

10. Clinical patterns and major causes of infertility in Mongolia, Bayasgalan G, Naranbat D: J Obstet Gynaecol Res.2004 Oct; 30(5):386-93, https://www.ncbi.nlm.nih.gov/pubmed/15327454

11. Causes of infertility in women at reproductive age, Health Science Journal 3(2):8087, April2009,https://www.researchgate.net/publication 1289067504_Causes_of_infertility_in_women_at_repro ductive_age

12. Genital tuberculosis: a leading cause for infertility in women seeking assisted conception in North India. Singh $N$, Sumana G, Mittal https://www.ncbi.nlm.nih.gov/pubmed/18283475

13. Analysis of causes and clinical pattern of infertility in couples coming to a tertiary care centre in Bihar, India.Available from: https://www.researchgate.net/publication/317125286_ Analysis_of_causes_and_clinical_pattern_of_infertility_ $i$ n_couples_coming_to_a_tertiary_care_centre_in_Bihar_I ndia [accessed Jan 02 2019] 